\title{
The HU177 Collagen Epitope Controls Melanoma Cell Migration and Experimental Metastasis by a CDK5/YAP-Dependent Mechanism
}

\author{
Jennifer M. Caron, XiangHua Han, Liangru Contois, Calvin P.H. Vary, and Peter C. Brooks
}

From the Center for Molecular Medicine, Maine Medical Center Research Institute, Scarborough, Maine

Accepted for publication

June 15, 2018.

Address correspondence to Peter C. Brooks, Ph.D., Maine Medical Center Research Institute, Center for Molecular Medicine, 81 Research Dr., Scarborough, ME 04074. E-mail: brookp1@mmc.org.

\begin{abstract}
Stromal components not only help form the structure of neoplasms such as melanomas, but they also functionally contribute to their malignant phenotype. Thus, uncovering signaling pathways that integrate the behavior of both tumor and stromal cells may provide unique opportunities for the development of more effective strategies to control tumor progression. In this regard, extracellular matrix-mediated signaling plays a role in coordinating the behavior of both tumor and stromal cells. Here, evidence is provided that targeting a cryptic region of the extracellular matrix protein collagen (HU177 epitope) inhibits melanoma tumor growth and metastasis and reduces angiogenesis and the accumulation of $\alpha$-SMA-expressing stromal cell in these tumors. The current study suggests that the ability of the HU177 epitope to control melanoma cell migration and metastasis depends on the transcriptional coactivator Yes-associated protein (YAP). Melanoma cell interactions with the HU177 epitope promoted nuclear accumulation of YAP by a cyclin-dependent kinase-5-associated mechanism. These findings provide new insights into the mechanism by which the anti-HU177 antibody inhibits metastasis, and uncovers an unknown signaling pathway by which the HU177 epitope selectively reprograms melanoma cells by regulating nuclear localization of YAP. This study helps to define a potential new therapeutic strategy to control melanoma tumor growth and metastasis that might be used alone or in combination with other therapeutics. (Am J Pathol 2018, 188: 2356-2368; https:// doi.org/10.1016/j.ajpath.2018.06.017)
\end{abstract}

The importance of the tumor microenvironment in controlling malignant cell growth and metastasis is well accepted. However, without a more detailed understanding of the mechanisms by which the tumor microenvironment regulates malignant cell behavior, developing more effective clinical strategies aimed at targeting the tumor stroma will be slow to emerge. The tumor microenvironment can be organized into cellular and noncellular compartments. Important constituents of the cellular compartment include stromal cells that regulate tumor growth and metastasis such as endothelial cells, cancer-associated fibroblasts (CAFs), and multiple cell types that compose the innate and adaptive immune system. ${ }^{1,2}$ Although therapeutic strategies have been designed to target stromal cells, a more comprehensive approach that simultaneously impacts multiple stromal cell types and tumor cells may result in the development of more effective therapeutics.
Comprising proteins of the noncellular compartment, the extracellular matrix (ECM) is not simply a passive structural support but represents a common control point that governs diverse signaling pathways that regulate cell adhesion, migration, gene expression, proliferation, and cell survival. $^{3,4}$ The ability of the ECM to modulate cell behavior is largely mediated through interactions with a family of transmembrane cell surface receptors called integrins. ${ }^{5}$ Although the strategy of inhibiting integrin-ECM signaling by directly targeting integrins such

\footnotetext{
Supported in part by NIH grant CA196739 (P.C.B.) and institutional support from Maine Medical Center. This work also utilized the services of the molecular phenotyping core facility at Maine Medical Center Research Institute, funded by NIH grant P20GM106391 COBRE in Stem and Progenitor Cell Biology and Regenerative Medicine.

Disclosures: P.C.B. and C.P.H.V. hold equity in CryptoMedix Inc.
} 
as $\alpha v \beta 3$ and $\alpha 5 \beta 1$ have been tested clinically, these approaches have resulted in limited success. ${ }^{6}$ Possible explanations for this limited activity include the fact that the final output of integrin signaling can be either pro- or antitumorigenic depending on the particular integrin and what specific cell types they are expressed in. ${ }^{6-8}$ In addition, integrin signaling also depends on the molecular properties of their ligands. For example, different ligand molecules that bind the same integrin may stimulate different signaling events, leading to distinct and sometime opposing cellular behavior. ${ }^{9-11}$

An alternative strategy for inhibiting integrin-ECM signaling involves direct targeting of integrin-binding sites within the ligand molecule itself. ${ }^{12-17}$ This strategy would allow precise inhibition of integrin-ECM signaling only at sites where the specific ECM ligand is present, thus avoiding the pitfalls associated with globally inhibiting all integrin signaling. However, given the broad expression of ECM molecules, a unique strategy is needed that would limit the impact of this approach to selected tissue microenvironments. To this end, our laboratory has been focused on uncovering mechanisms by which cryptic integrin binding sites selectively exposed within structurally altered forms of ECM proteins exert control over cell behavior. The presence of structurally altered ECM is a common feature of the basement membranes of tumor-associated vessels. ${ }^{12-17}$ The generation of structurally altered or denatured collagen, which contains cryptic binding sites for a subset of integrins, provides a highly selective targeting strategy. The altered structure of vascular basement membranes within tumors may also represent sites for tumor cells to gain access to the host circulation, thereby facilitating tumor metastasis. ${ }^{13,15}$

Our previous studies have identified a cryptic regulatory region of collagen termed the HU177 epitope. ${ }^{14,17}$ The HUI77 epitope has been defined as a collagen consensus sequence containing variations on the amino acid sequence PGxPG where $\mathrm{P}$ represents proline, $\mathrm{G}$ represents glycine, and $\mathrm{x}$ can represent other amino acids in collagen. ${ }^{14,17}$ Under normal conditions, the HU177 epitope is hidden within the three-dimensional structure of collagen and is not exposed in a manner that allows receptor binding. ${ }^{14,17,18}$ However, denaturation of collagen, for example by proteolytic enzymes, results in exposure of the HU177 epitope. ${ }^{19}$ Cellular interactions with the HU177 epitope can be mediated by integrin $\alpha 10 \beta 1 .{ }^{17}$ We developed an antibody that selectively binds to the HU177 epitope, but not to intact collagen. ${ }^{14,17,18,20}$ This antibody selectively inhibits $\alpha 10 \beta 1$ mediated binding to this epitope. ${ }^{17}$ By contrast, the antiHU177 antibody does not inhibit cellular binding to intact collagen. ${ }^{14,17,20}$ This unique antibody binding characteristic allows for inhibition of integrin-mediated cellular interactions only at sites in which the HU177 epitope is generated.

The anti-HU177 antibody can inhibit angiogenesis and the growth of breast and ovarian carcinomas in vivo. ${ }^{17,21}$
These and other data led to the development of a humanized version ${ }^{18,21}$ of this antibody (D93/TRC093) and its evaluation in a phase I clinical trial. ${ }^{22}$ Results from this study were encouraging, with no dose-limiting toxicities. Moreover, $26 \%$ of the treated patients exhibited clinical responses including stable disease and, surprisingly, the regression of a malignant liver lesion in a subject with ovarian cancer. ${ }^{22}$ Although this clinical study was encouraging, it is not known whether this strategy might provide therapeutic benefit to individuals suffering from melanoma, as no melanoma patients were enrolled in this trial. ${ }^{22}$ Importantly, the detailed mechanisms by which the antiHU177 antibody inhibits tumor growth are not completely understood. Therefore, defining the molecular mechanisms by which the anti-HU177 antibody inhibits tumor growth will help optimize its use and therapeutic activity.

Here, evidence is provided that direct targeting of the HU177 epitope inhibits melanoma tumor growth. Tumors from treated mice exhibited reduced levels of angiogenesis and $\alpha$-smooth muscle actin ( $\alpha$-SMA)-expressing stromal cells. Targeting the HU177 epitope also directly impacts the behavior of the melanoma cells themselves, as the antiHU177 antibody inhibited B16F10 cell migration in vitro. Interestingly, our findings suggest that the ability of the anti-HU177 antibody to inhibit B16F10 melanoma cell migration and metastasis depended on the transcriptional coactivator Yes-associated protein (YAP), because knockdown of Yap prevented the ability of the anti-HU177 antibody from inhibiting these processes. Surprisingly, our studies indicate that $\mathrm{B} 16 \mathrm{~F} 10$ melanoma cell interactions with the HU177 epitope regulate the nuclear accumulation of YAP by a novel CDK5-dependent mechanism. Our findings not only provide new molecular insight into the mechanisms by which the anti-HU177 antibody inhibits metastasis, but also uncover a previously unknown signaling pathway by which the HU177 epitope selectively reprograms melanoma cells by regulating nuclear localization of YAP by a CDK5-dependent process. Collectively, this study helps to define a new therapeutic strategy that might be exploited clinically to control melanoma tumor growth and metastasis.

\section{Materials and Methods}

\section{Reagents, Chemicals, and Antibodies}

Bovine serum albumin (BSA), crystal violet, and collagen type-IV were from Sigma-Aldrich (St. Louis, MO). Anti-CD31 antibody was from BD Pharmingen (San Diego, CA). Anti- $\alpha$-SMA and anti-tyrosinase-related protein-1 (TRP-1) antibodies were from Abcam (Cambridge, MA). Anti- $\beta$-tubulin, anti- $\beta$-actin, and anti-YAP1 antibodies were from Santa Cruz Biotechnology (Santa Cruz, CA). Anti-talin, anti-phospho-talin serine 425, anti-CDK5, and anti-CDK5 phosphorylated serine-127 antibodies were from Cell Signaling Technology (Danvers, MA). 
Anti-TATA-binding protein (TBP) antibody was from Cell Signaling Technology. Antibody to $\alpha 10 \beta 1$ was from Millipore (Burlington, MA). Secondary antibodies were from Promega (Madison, WI). Humanized anti-HU177 Mab D93/TRC093 was provided by TRACON Pharmaceuticals (San Diego, CA). Alexa 594- and 488-labeled secondary antibodies were from Invitrogen (Carlsbad, CA). The CDK5 inhibitor (roscovitine) was from Selleckchem (San Diego, CA).

\section{Cells and Cell Culture}

B16F10 cells were from ATCC (Manassas, VA) and cultured in Dulbecco's modified Eagle's medium (DMEM) in the presence of $10 \%$ fetal bovine serum, $1 \%$ penicillinstreptomycin, and $1 \%$ sodium pyruvate. C8161 melanoma cells were a gift from Dr. Mary Hendrix (Children's Memorial Hospital, Chicago, IL). C8161 cells were cultured in RPMI in the presence of 5\% fetal bovine serum, $1 \%$ penicillin-streptomycin, and $1 \%$ sodium pyruvate. Human dermal fibroblasts were obtained from ScienCell (Carlsbad, CA) and cultured in fibroblast growth medium with $2 \%$ fetal bovine serum (ScienCell).

\section{Nuclear Protein Extraction}

Cells were washed and serum starved for 18 hours in DMEM. Cells were harvested and kept in suspension for 2 hours in DMEM, and 500,000 cells resuspended in adhesion buffer (RPMI 1640 medium containing $1 \mathrm{mmol} / \mathrm{L}$ $\mathrm{MgCl}_{2}, 0.2 \mathrm{mmol} / \mathrm{L} \mathrm{MnCl}_{2}$ ) were seeded on plates coated with $5 \mu \mathrm{g} / \mathrm{mL}$ denatured (boiled for 15 minutes) collagen IV. In similar experiments, cells were seeded on denatured collagen IV-coated plates preblocked with $10 \mu \mathrm{g} / \mathrm{mL}$ antiHU177 or nonspecific antibody. After incubating for 15 minutes, adherent and nonadherent cells were harvested. The nuclear protein was extracted using NE-PER nuclear and cytoplasmic extraction reagents (Thermo Fisher Scientific, Waltham, MA).

\section{Viral Vectors and Transduction}

Lentiviral vectors (pLKO.1 based) encoding shRNAs specific to the mouse Yap and nontargeting vectors developed by the RNAi Consortium were obtained from GE Healthcare Life Science (Lafayette, CO). The effective targeting sequence of the Yap gene was $5^{\prime}$-TTCTTTATCTAGCTTGGTGGC- $3^{\prime}$. Lentivirus was packaged in the recombinant viral vector core facility at Maine Medical Center Research Institute. Cells transduced with the shRNA viruses were selected in medium containing $3 \mu \mathrm{g} / \mathrm{mL}$ puromycin (Invitrogen). Retroviral GFP vectors (P-GFP-VRS based) encoding shRNAs specific to mouse $C d k 5$ and nontargeting shRNA were obtained from Origene Technologies (Rockville, MD). The effective targeting sequence of the Cdk5 gene was 5'-CGTCCGCTGCTACTCTGCT-
GAGGTGGTCA- $3^{\prime}$. Plasmids were transfected into B16F10 cells using Lipofectamine 3000 (Invitrogen). Cells were selected in medium containing $3 \mu \mathrm{g} / \mathrm{mL}$ puromycin.

\section{Analysis of Protein Expression}

Frozen sections from tumors ( $n=4$ to 5 per condition) were fixed in 50\% methanol $50 \%$ acetone and blocked with $2.0 \%$ BSA in phosphate-buffered saline. For quantification of angiogenesis, sections were stained with anti-CD31 (dilution 1:300) followed by incubation with Alexa594-labeled secondary antibody. Vessel counts were taken from five $\times 100$ fields from each of the four tumors from every condition. For analysis of CAF-like stromal cells, sections of tumors were stained with anti- $\alpha$-SMA (dilution 1:1000) antibody followed by incubation with Alexa594-labeled secondary. ImageJ software version $1.52 \mathrm{a}$ (NIH, Bethesda, MD; https://imagej.nih.gov/ij) analysis was used for quantification from five $\times 100$ fields from each of the four to five tumors from every condition. Analysis to confirm the presence of B16F10 cells in chick lungs was performed by staining sections with anti-TRP-1 antibody $(1: 100)$.

\section{Cell Adhesion Assays}

Wells from nonculture plates were coated with $5 \mu \mathrm{g} / \mathrm{mL}$ of native or denatured collagen type-IV. ${ }^{17}$ Tumor cells were suspended in buffer (DMEM containing $1 \mathrm{mmol} / \mathrm{L} \mathrm{MgCl}$, $0.2 \mathrm{mmol} / \mathrm{L} \mathrm{MnCl}_{2}$, and $0.5 \% \mathrm{BSA}$ ), and $1 \times 10^{5}$ cells were added to the wells in the presence of anti-HU177 or nonspecific antibodies $(100 \mu \mathrm{g} / \mathrm{mL})$. Cells were allowed to attach for 10 minutes at $37^{\circ} \mathrm{C}$. Nonattached cells were removed and attached cells stained with crystal violet. Cell adhesion was quantified by measuring the optical density of eluted dye. ${ }^{17}$ Assays were completed at least three times.

\section{Cell Migration Assays}

Membranes from Transwells were coated with $15 \mu \mathrm{g} / \mathrm{mL}$ of native or denatured collagen type-IV. ${ }^{17}$ Cells were resuspended in buffer (DMEM containing $1 \mathrm{mmol} / \mathrm{L} \mathrm{MgCl}_{2}$, $0.2 \mathrm{mmol} / \mathrm{L} \mathrm{MnCl}_{2}$, and $\left.0.5 \% \mathrm{BSA}\right)$ in the presence $(50 \mu \mathrm{L})$ of $10 \times$ concentrated serum-free human dermal fibroblast-conditioned medium and in the presence of anti-HU177 epitope or nonspecific control antibodies $(100 \mu \mathrm{g} / \mathrm{mL})$. For CDK5 inhibitor experiments, tumor cells were incubated for 18 hours with either $10 \mu \mathrm{mol} / \mathrm{L}$ CDK5 inhibitor or dimethyl sulfoxide. Cells were allowed to migrate for 5 hours at $37^{\circ} \mathrm{C}$. For migration assays to assess the effects of preattachment to collagen, B16F10 cells were allowed to attach to intact native or denatured collagen typeIV $(5.0 \mu \mathrm{g} / \mathrm{mL})$ for 1 hour. Cells were detached with Versene Solution (Irvine Scientific, Santa Ana, CA), washed, and migration was examined. Migration was quantified by staining cells with crystal violet that had migrated to the 
lower surface of the Transwell membranes (Corning, Corning, NY) followed by destaining the cells and measuring the eluted dye. ${ }^{17}$ Assays were completed at least three times.

\section{Tumor Growth Assays}

Mice (C57BL/6 or NCRNU-F) were injected subcutaneously with $0.5 \times 10^{6} \mathrm{~B} 16 \mathrm{~F} 10$ cells or $2.0 \times 10^{6} \mathrm{C} 8161$ cells. Tumors were allowed to form for 3 to 5 days and then mice were injected (i.p.) with anti-HU177 or nonspecific control antibodies ( 0 to $100 \mu \mathrm{g} / \mathrm{mouse}$ ) $3 \times$ per week for either 12 days for the B16F10 tumor model or 21 days for the $\mathrm{C} 8161$ tumor model. Tumors were measured with calipers and volumes calculated using the formula: $\mathrm{V}=\mathrm{L}^{2} \times \mathrm{W} / 2$, where $\mathrm{V}=$ volume, $\mathrm{L}=$ length, and $\mathrm{W}=$ width. For tumor growth in the chick embryo model, B16F10 cells $\left(2 \times 10^{5}\right.$ cells per chick) were seeded on the chorioallantoic membranes of 10-day-old chick embryos in the presence of nonspecific or anti-HU177 $(100 \mu \mathrm{g})$ antibodies. Tumor weights were determined at day 7. All in vivo tumor growth experiments were conducted under an approved institutional animal care and use committee protocol from Maine Medical Center Research Institute.

\section{Chick Lung Metastasis Assay}

B16F10 cells were washed and cells $\left(2.5 \times 10^{5}\right)$ were resuspended in phosphate-buffered saline containing either nonspecific control or anti-HU177 antibody $(100 \mu \mathrm{g})$ and injected (i.v.) into 12 -day-old chicks. ${ }^{13,15}$ For metastasis assays to assess the effects of preattachment to collagen, B16F10 cells were allowed to attach to intact or denatured collagen $(5.0 \mu \mathrm{g} / \mathrm{mL})$ for 1 hour. Cells were detached with Versene, resuspended in phosphate-buffered saline, and injected as described above. The numbers of pigmented lung lesions were counted on both lobes of the lungs at the end of a 7-day incubation period. Experiments were completed two to four times with five to nine chicks per condition. All in vivo metastasis experiments were conducted under an approved institutional animal care and use committee protocol from Maine Medical Center Research Institute.

\section{Western Blot Analysis}

Tumor cells were seeded on denatured collagen-IV-coated nontissue culture plates pretreated with $10 \mu \mathrm{g} / \mathrm{mL}$ of nonspecific control antibody or anti-HU177 antibody, and cells were allowed to bind for 10 to 15 minutes then lysed in radioimmunoprecipitation assay buffer with $1 \times$ protease inhibitor cocktail (Santa Cruz Biotechnology). Cell lysates were separated by SDS-PAGE. Membranes were probed with antibodies directed to $\alpha 10 \beta 1$, total and phosphorylated talin, total and phosphorylated CDK5, total nuclear YAP or phosphorylated YAP, control proteins $\beta$-actin, $\beta$-tubulin, or TBP. Western blot analyses were performed at least three to eight times. ImageJ software was used for quantification of relative changes in protein as described. ${ }^{17}$

\section{Statistical Analysis}

Statistical analysis was performed using the Prism/GraphPad version-6 program (GraphPad Software, La Jolla, CA). Data were analyzed for significance using $t$-test and Wilcoxon ranked sums test. $P<0.05$ was considered significant.

\section{Results}

Anti-HU177 Antibody Inhibits Tumor Growth, Angiogenesis, and Accumulation of $\alpha$-SMA-Expressing Stromal Cells in Melanoma

The anti-HU177 antibody can inhibit the growth of stromalrich breast and ovarian carcinomas in vivo. ${ }^{17,21}$ However, little is known concerning the impact this strategy might have on melanoma cell behavior or metastasis. Collagen remodeling leads to the generation of the HU177 epitope during melanoma development. A circulating form of the HU177 epitope was detected in human subjects diagnosed with melanoma, and the levels of the HU177 epitope correlated with tumor thickness and a worse prognosis. ${ }^{23,24}$

To examine the effects of anti-HU177 antibody on melanoma tumor growth, two distinct melanoma cell lines, including metastatic murine $\mathrm{B} 16 \mathrm{~F} 10$ cells and human C8161 melanoma cells, were used. As expected, the HU177 epitope was detected within these melanomas growing in mice (Figure 1A). Consistent with previously published studies, ${ }^{17,18}$ little if any of the HU177 collagen epitope was detected in normal tissues, including, lung, liver, and spleen (Supplemental Figure S1, A-C). Next, melanoma cells were injected in mice, and the effects of anti-HU177 antibody were assessed. Anti-HU177 antibody dosedependently inhibited B16F10 tumors (Figure 1B) with a maximal inhibition of approximately $50 \%$ observed at an antibody concentration of $100 \mu \mathrm{g} /$ mouse injected three times per week. Anti-HU177 antibody administered at a concentration of $100 \mu \mathrm{g} /$ mouse three times per week also significantly inhibited C8161 tumors growth (Figure 1C), indicating that the antitumor activity was not restricted to a single melanoma model. To further analyze the effects of the anti-HU177 antibody on melanoma, B16F10 tumors were studied. Tumor sections from control and anti-HU177 antibody-treated mice were examined for tumor angiogenesis and $\alpha$-SMA-expressing stromal cells by staining B16F10 tumors with antibodies directed to either CD31 or $\alpha$-SMA. Quantification indicated approximately $45 \%$ inhibition of tumor angiogenesis (Figure 1D) and over 60\% inhibition of accumulation of $\alpha$-SMA-expressing stromal cells (Figure 1E). These data are consistent with previous studies ${ }^{17}$ suggesting that the HU177 collagen epitope can control stromal cell behavior. 
A
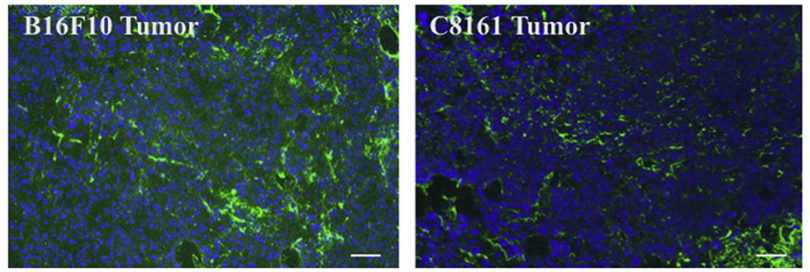

C8161 Melanoma

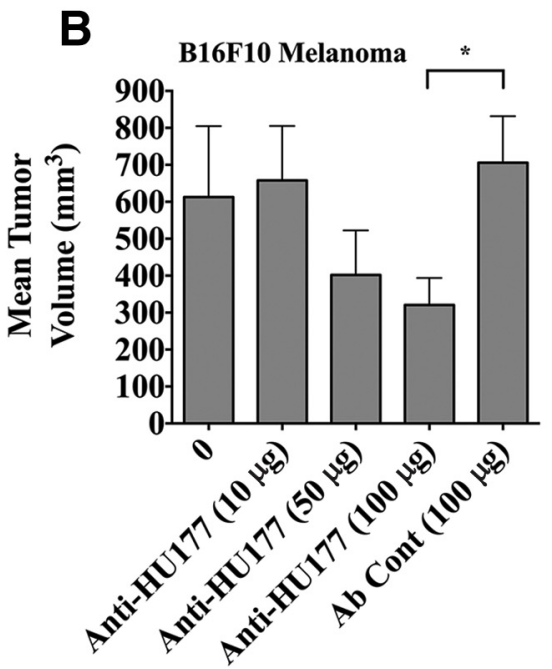

D

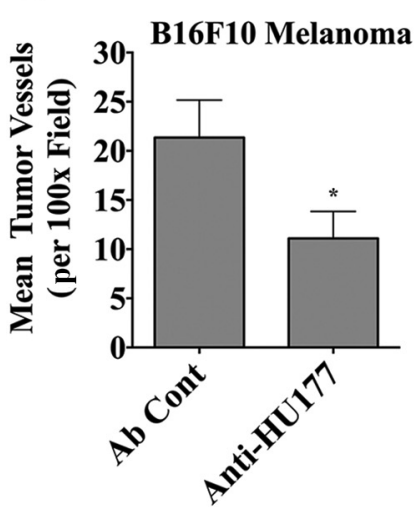

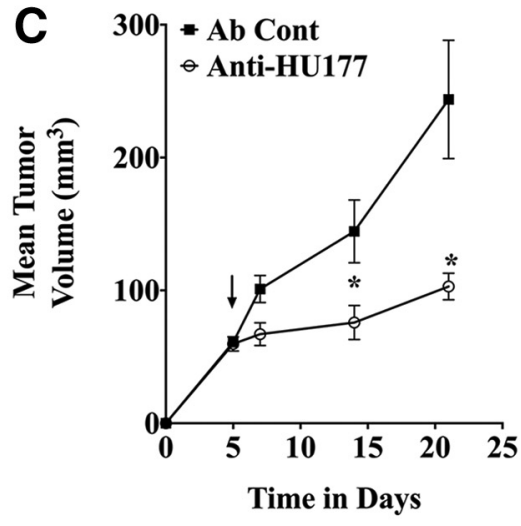

$\mathbf{E}$

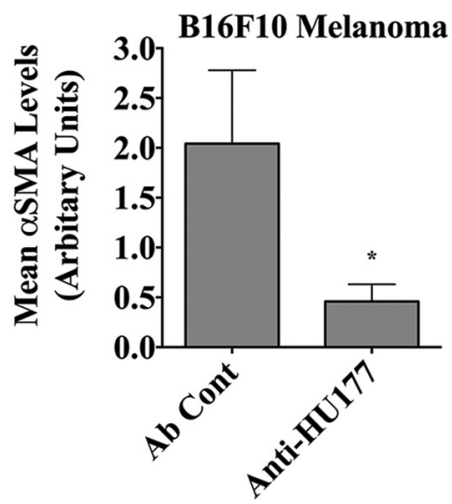

Figure 1 The HU177 epitope regulates melanoma-associated stromal cell accumulation and tumor growth. A: Examples of the HU177 epitope (green) in B16F10 and C8161 tumors. B: Quantification of the effects of anti-HU177 antibody on B16F10 tumor growth on day 12. C: Quantification of the effects of anti-HU177 antibody $(100 \mu \mathrm{g} /$ mouse $3 \times$ per week) on $\mathrm{C} 8161$ melanoma tumor growth. Arrow indicates start of antibody treatment on day 5. D: Sections from tumors (five fields per section) were stained with anti-CD31 antibody. E: Sections from tumors (five fields per section) were stained with anti- $\alpha$-SMA antibody. Data are expressed as means \pm SEM. $n=6$ to 8 animals per condition (B); $n=8$ animals per condition (C); $n=4$ tumors per condition (D). Scale bars $=50 \mu \mathrm{m}$. Original magnification, $\times 200$. ${ }^{*} P<0.05$ versus control antibody. Ab Cont, control antibody.

\section{Anti-HU177 Antibody Inhibits Melanoma Cell Migration and Experimental Metastasis}

The majority of deaths from melanomas result from metastasis. ${ }^{25}$ Tumors can recruit and activate stromal fibroblasts and in turn, these stromal cells can reciprocally stimulate tumor cell migration and metastasis. ${ }^{25,26}$ Therefore, we determined whether the HU177 epitope might regulate stromal cell-induced migration of melanoma cells. Serum-free conditioned medium (CM) was collected and concentrated from a variant of human dermal fibroblasts previously shown to exhibit characteristics of CAFs. ${ }^{17}$ Stimulation of B16F10 cells with $\mathrm{CM}$ from CAF-like stromal cells induced migration as compared to control medium (Figure 2A). Next, it was examined whether blocking B16F10 cell interactions with the HU177 epitope altered this induced migration. AntiHU177 antibody inhibited B16F10 cell migration induced by CAF-like cells (Figure 2A).

Tumor cell migration across the collagen-rich vascular basement membrane is one of the many steps that play roles in melanoma metastasis. ${ }^{25,26}$ It was first examined whether direct contact of $\mathrm{B} 16 \mathrm{~F} 10$ cells with denatured collagen may stimulate enhanced migration. To examine this possibility, B16F10 cells were allowed to preattach to intact collagen (Nat-Coll-IV) or denatured collagen (Den-Coll-IV) for 1 hour. Cells were next harvested and subsequently tested for their ability to migrate. Surprisingly, B16F10 cells that were allowed to bind denatured collagen, exhibited approximately $40 \%$ increase in migration as compared with B16F10 cells that were allowed to bind to intact collagen (Figure 2B). 
A

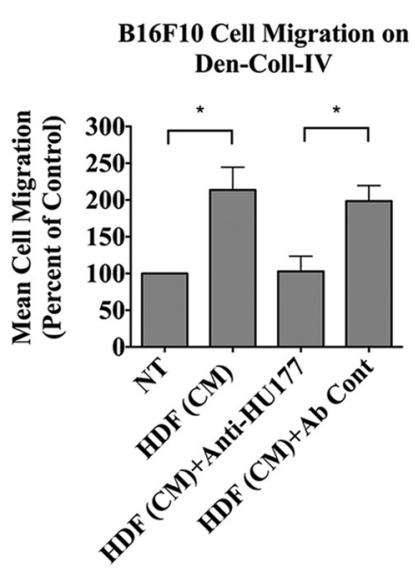

B

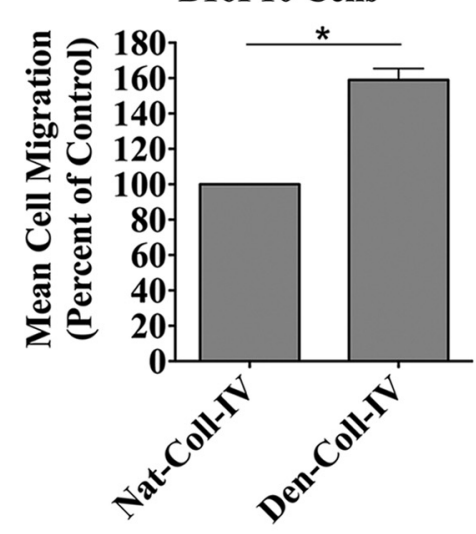

D
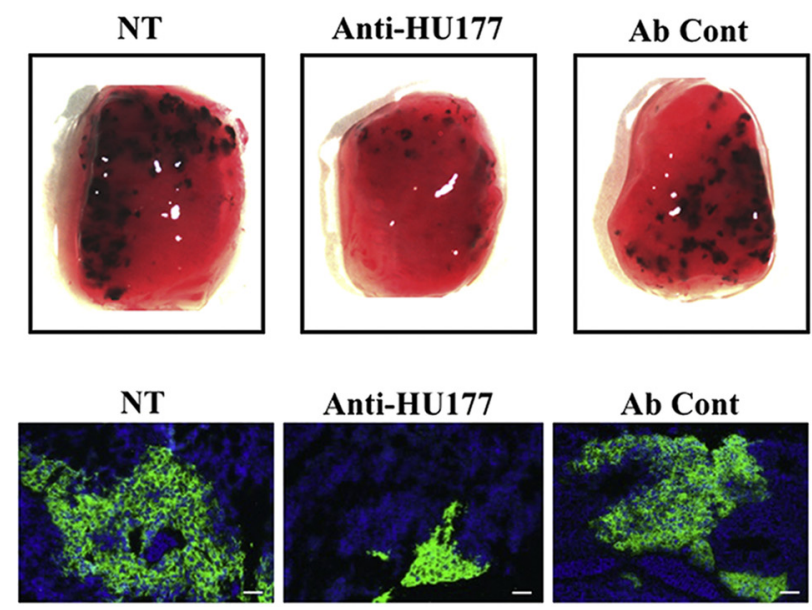
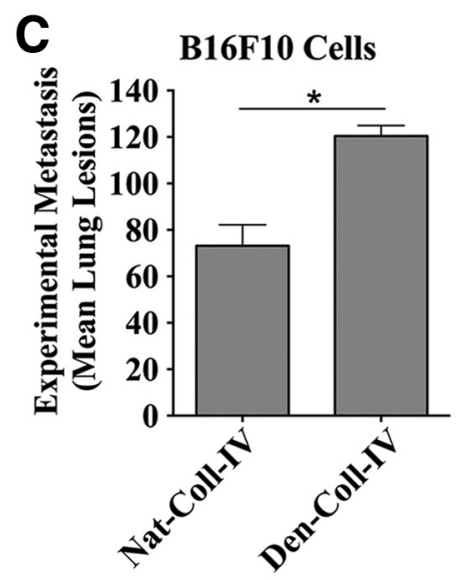

$\mathbf{E}$

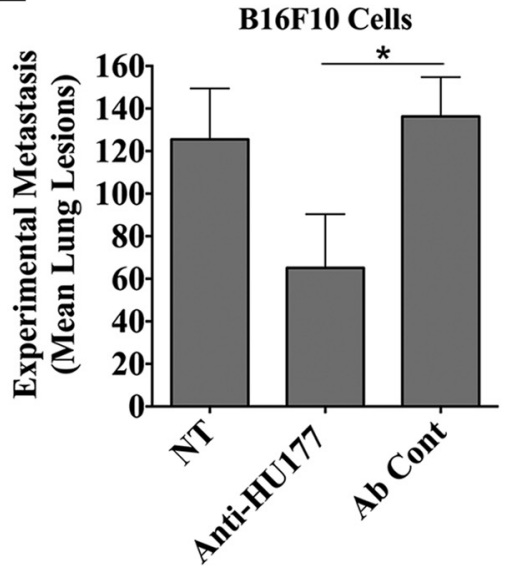

Figure 2 Targeting the HU177 epitope inhibits B16F10 cell migration and experimental metastasis. A: B16F10 cells were stimulated to migrate on denatured collagen by incubation with $10 \times$ concentrated serum-free conditioned medium from CAF-like dermal fibroblast. B: B16F10 cells were seeded on intact collagen or denatured collagen and allowed to bind for 1 hour. Cells were added to a Transwell migration chamber and allowed to migrate on denatured collagen. C: B16F10 cells were seeded on intact collagen or denatured collagen and allowed to bind for 1 hour. B16F10 cells were next injected systemically into chick embryos. Experiments were performed twice. D and E: B16F10 cells were injected systemically into chick embryos in the presence or absence of antiHU177 or control nonspecific antibody. D: Examples of pigmented B16F10 lung tumors (top panel) or TRP-1-expressing B16F10 lung lesions (bottom panel) from each condition. E: Quantification of pigmented B16F10 lung colonization. Experiments were performed at least three times. Data are expressed as means \pm SEM. $n=4$ experiments (A and B); $n=6$ to 7 animals per condition (C); $n=6$ to 8 animals per condition (D and E). Scale bars $=50 \mu \mathrm{m}$. ${ }^{*} P<0.05$. CM, conditioned medium; Den-Coll-IV, denatured collagen; HDF, human dermal fibroblast; Nat-Coll-IV, intact collagen; NT, no treatment.

Using a similar strategy, B16F10 cells were allowed to preattach for 1 hour to intact collagen or denatured collagen then systemically injected into chick embryos and experimental lung metastasis was quantified 7 days later. ${ }^{13,15} \mathrm{~B} 16 \mathrm{~F} 10$ cells that were allowed to attach to denatured collagen before injection exhibited enhanced levels of experimental metastasis as compared with B16F10 cells allowed to preattach to intact collagen (Figure 2C). These surprising observations suggest that B16F10 cell interactions with denatured collagen may initiate a priming or reprogramming event that stimulates enhanced lung colonization. Given that multiple integrin binding sites are present in denatured collagen, it was next examined whether the specific HU177 epitope plays a role in lung colonization. Systemic injection of B16F10 cells formed lung tumors, which were readily detected as either pigmented lung surface lesions or tyrosinase-related protein-1 (TRP-1)-positive lesions (Figure 2D). Importantly, treatment with anti-HU177 antibody inhibited experimental metastasis by approximately $60 \%$ (Figure 2E). These data indicate that the HU177 epitope plays a role in melanoma cell migration in vitro and experimental metastasis in vivo.

Blocking Interactions with the HU177 Epitope Inhibits Phosphorylation of Talin and CDK5

The integrin $\alpha 10 \beta 1$ can serve as a receptor for the HU177 epitope, ${ }^{17}$ and this integrin is up-regulated in metastatic melanoma $^{27}$ and is expressed in $\mathrm{B} 16 \mathrm{~F} 10$ cells 
(Supplemental Figure S1D). To begin to define mechanisms that contribute to the ability of the anti-HU177 antibody to inhibit melanoma, effector molecules that operate down stream of integrin binding were examined. The adapter molecule talin facilitates molecular linkages between integrins and the actin cytoskeleton, and plays multiple roles in cell migration. ${ }^{28,29}$ Therefore, the effects of anti-HU177 antibody were first examined on talin phosphorylation. Phosphorylation of talin at serine residue 425 regulates focal adhesion dynamics and actin remodeling ${ }^{30}$ critical events that control cell migration. To examine talin phosphorylation, cells were allowed to bind denatured collagen-coated plates for 15 minutes that were pretreated with nonspecific control antibody or anti-HU177 antibody followed by preparation of whole-cell lysates. Selectively blocking B16F10 cell interactions with the HU177 epitope reduced phosphorylation of talin by approximately $35 \%$ (Figure 3, A and B). Phosphorylation of serine- 425 in talin is mediated by $\mathrm{CDK} 5^{30}$ and CDK5 regulates actin dynamics, cellular migration, and metastasis in melanoma cells. ${ }^{31,32}$ Therefore, a similar approach as described above was used, and the effects of anti-HU177 antibody were examined on phosphorylation of CDK5 at Tyrosine-15, a site shown to be associated with enhanced CDK5 activity. ${ }^{33}$ Selectively blocking B16F10 cell interactions with the HU177 epitope inhibited CDK5 phosphorylation by approximately $65 \%$ (Figure 3, C and D). To examine whether CDK5 plays a role in mediating B16F10 cell migration on native and denatured collagen, migration assays were performed in the presence of an inhibitor of CDK5. Migration of B16F10 cells on either native intact or denatured collagen was inhibited by approximately $30 \%$ to $40 \%$, respectively (Figure 3, E and F). To confirm the relevance of CDK5 in B16F10 cell migration, the expression of $C d k 5$ was knocked down by shRNA (Supplemental Figure S1E), and migration of CDK5-KD cells on either native or denatured collagen was inhibited by approximately $25 \%$ to $40 \%$, respectively (Figure 3, G and $\mathrm{H}$ ). These findings are consistent with a role for $\mathrm{CDK} 5$ in $\mathrm{B} 16 \mathrm{~F} 10$ cell migration on either native or denatured collagen.
A

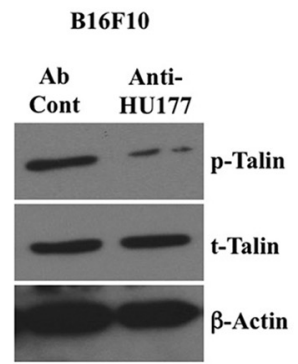

$\mathbf{E}$

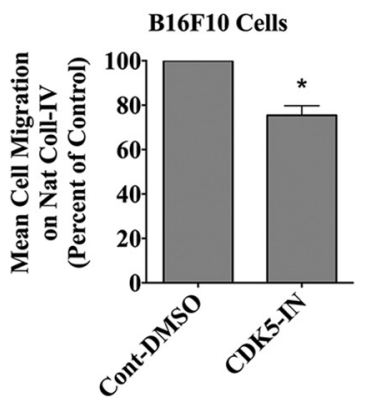

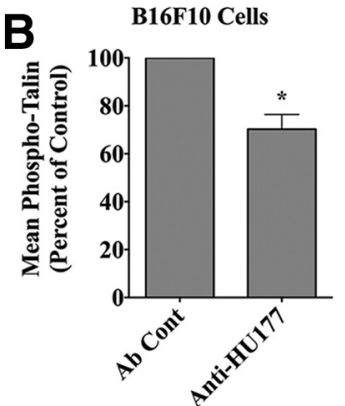

$\mathbf{F}$

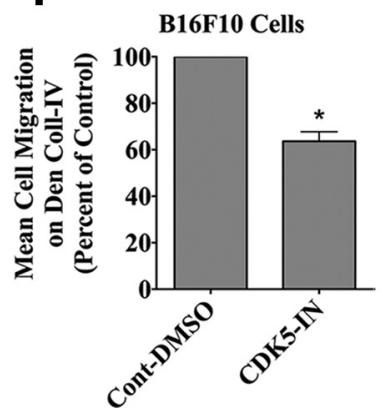

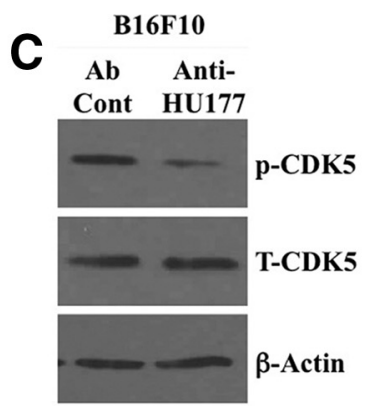

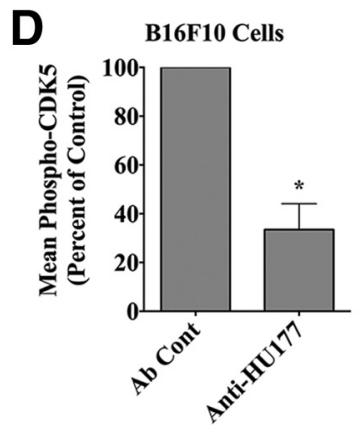

G

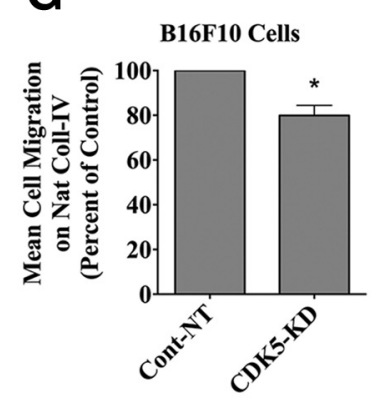

H

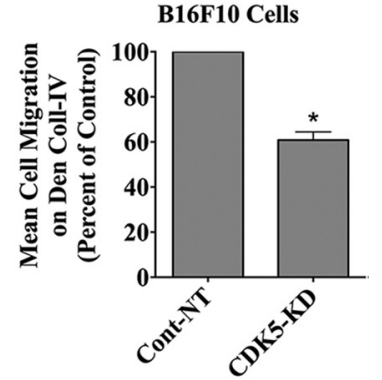

Figure 3 Targeting the HU177 epitope inhibits phosphorylation of talin and CDK5 in melanoma cells. A: Example of a western blot for total talin and talin phosphorylated at Ser-425 from cells attached to denatured collagen pretreated $(10 \mu \mathrm{g} / \mathrm{ml})$ with control antibody or anti-HU177 antibody. B: Quantification of mean relative change in talin phosphorylation. C: Example of Western blot analysis for total and phosphorylated CDK5 in cells attached to denatured collagen pretreated $(10 \mu \mathrm{g} / \mathrm{mL})$ with control antibody or anti-HU177 collagen epitope antibody. D: Quantification of mean relative change in CDK5 phosphorylation. E: Quantification of mean migration on native collagen of control-treated and CDK5 inhibitor-treated B16F10 cells. F: Quantification of mean migration on denatured collagen of control-treated and CDK5 inhibitor-treated B16F10 cells. G: Quantification of mean migration of control-transfected and Cdk5 shRNA-transfected B16F10 cells on native collagen. H: Quantification of mean migration of control-transfected and Cdk5 shRNA-transfected B16F10 cells on denatured collagen. Data are expressed as means \pm SEM. $n=4$ experiments (B, F-H); $n=6$ experiments (D); $n=3$ experiments (E). ${ }^{*} P<0.05$ versus control. Ab Cont, control antibody; Anti-HU177, anti-HU177 epitope antibody; CDK5-IN, CDK5 inhibitor-treated; CDK5-KD, Cdk5 shRNA-transfected; ContDMS0, dimethyl sulfoxide-treated control; Cont-NT, control-transfected; p-CDK5, phosphorylated CDK5; p-Talin, phosphorylated Ser-425; T-CDK5, total CDK5; T-Talin, total talin. 
The Ability of the HU177 Epitope to Control B16F10 Cell Migration on Denatured Collagen Depends on CDK5

To determine the role of CDK5 in regulating migration mediated specifically by the HU177 epitope, the effects of anti-HU177 antibody were examined on adhesion and migration using B16F10 cell variants in which the levels of $C d k 5$ had been knocked down. Adhesion of control transfected B16F10 cells to denatured collagen was significantly $(P<0.05)$ inhibited by anti-HU177 antibody (Figure 4B) whereas, as expected, adhesion to native collagen (Figure 4A) was not affected because the anti-HU177 antibody does not bind to native collagen. Importantly, anti-HU177 antibody exhibited little ability to inhibit adhesion to either native or denatured collagen of B16F10 cells in which $C d k 5$ expression was knocked down (Figure 4, C and D). In similar studies, although migration of control transfected B16F10 cells on denatured collagen was significantly $(P<0.05)$ inhibited by anti-HU177 antibody (Figure 4F), the anti-HU177 antibody exhibited no significant inhibitory activity on migration on native collagen (Figure 4E). Finally, anti-HU177 antibody failed to inhibit migration on native collagen using B16F10 cells in which $C d k 5$ expression was knocked down (Figure 4G) and had only minimal inhibitory activity on the ability of these cells to migrate on denatured collagen (Figure 4H). These data suggest that the ability of the HU177 epitope to control melanoma cell adhesion and migration depends on CDK5.

\section{CDK5 Plays a Role in Controlling Nuclear Accumulation of YAP in B16F10 Cells Binding to Denatured Collagen}

CDK5 regulates cell migration, actin polymerization, and focal adhesion dynamics. ${ }^{32}$ Integrin receptors and actin polymerization play key roles in controlling activation and subcellular localization of YAP, which has been implicated in tumor cell migration and metastasis. ${ }^{34,35}$ Given the ability of the HU177 epitope to alter CDK5 phosphorylation, the effects of CDK5 were examined on nuclear YAP accumulation when cells were attached to denatured collagen. Treatment of B16F10 cells with a CDK5 inhibitor or reducing expression of $C d k 5$ (Figure 5, A-D) both resulted in reduction in the levels of nuclear YAP in cells attached to denatured collagen.
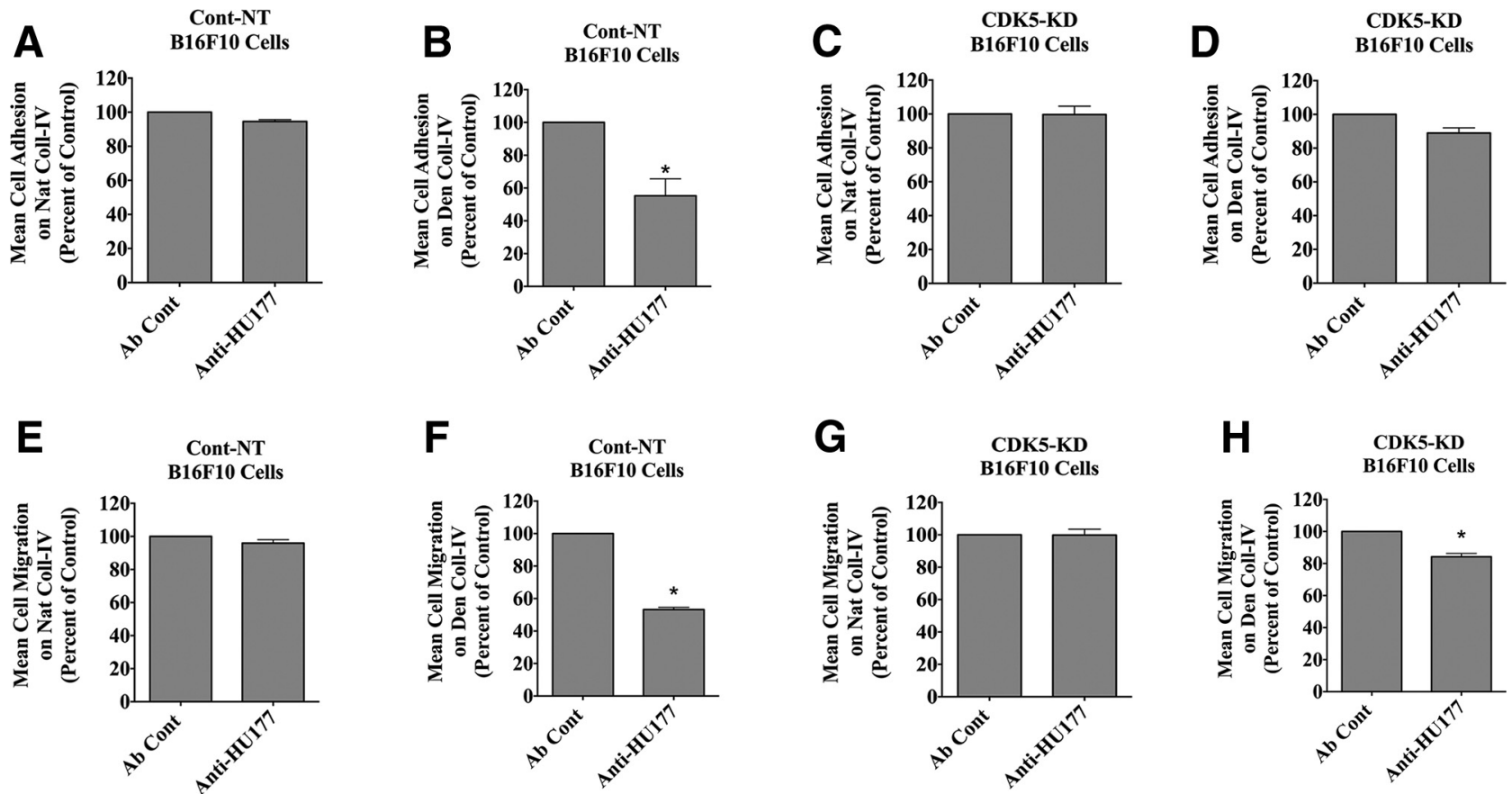

Figure 4 The ability of the HU177 epitope to control B16F10 cell adhesion and migration on denatured collagen depends on CDK5. A: Quantification of control-transfected B16F10 cell adhesion to native collagen in the presence of nonspecific control antibody and anti-HU177 epitope antibody. B: Quantification of control-transfected B16F10 cell adhesion to denatured collagen in the presence of nonspecific control antibody and anti-HU177 epitope antibody. C: Quantification of Cdk5 shRNA-transfected B16F10 cell adhesion to native collagen in the presence of nonspecific control antibody and anti-HU177 epitope antibody. D: Quantification of Cdk5 shRNA-transfected B16F10 cell adhesion to denatured collagen in the presence of nonspecific control antibody and anti-HU177 epitope antibody. E: Quantification of control-transfected B16F10 cell migration on native collagen in the presence of nonspecific control antibody and anti-HU177 epitope antibody. F: Quantification of control-transfected B16F10 cell migration on denatured collagen in the presence of nonspecific control antibody and anti-HU177 epitope antibody. G: Quantification of Cdk5 shRNA-transfected B16F10 cell migration on native collagen in the presence of nonspecific control antibody and anti-HU177 epitope antibody. H: Quantification of Cdk5 shRNA-transfected B16F10 cell migration on denatured collagen in the presence of nonspecific control antibody and anti-HU177 epitope antibody. Data are expressed as means \pm SEM. $n=3$ experiments $(\mathbf{A}-\mathbf{H})$. ${ }^{*} P<0.05$ versus Ab control. Ab Cont, control antibody; Anti-HU177, anti-HU177 epitope antibody; CDK5-KD, Cdk5 shRNA-transfected; Cont-NT, control-transfected. 
Next, it was examined whether the nuclear localization of YAP in melanoma cells attached to denatured collagen depends on interactions with the HU177 epitope. Selectively blocking B16F10 cell interaction with the HU177 epitope reduced nuclear accumulation of YAP (Figure 5, E and F). Studies indicate that subcellular localization of YAP can be controlled by its phosphorylation at serine residue 127 , which promotes interactions with 14-3-3 protein facilitating cytoplasmic retention. ${ }^{34}$ Selectively blocking B16F10 cell interaction with the HU177 epitope enhanced the levels of YAP phosphorylation by approximately $30 \%$ (Figure 5, $\mathrm{G}$ and $\mathrm{H})$. Taken together, these data provide evidence that nuclear accumulation of YAP in B16F10 cells binding to denatured collagen depends on interactions with the HU177 epitope and CDK5.

\section{YAP Plays a Role in the Ability of HU177 Epitope to Control B16F10 Cell Migration in Vitro and Experimental Metastasis in Vivo}

It was next determined whether the ability of the antiHU177 antibody to inhibit melanoma cell adhesion and migration depends on YAP. B16F10 cell variants with reduced levels of Yap (YAP-KD B16F10) were generated using shRNA (Supplemental Figure S1F) and the ability of these B16F10 cells to attach and migrate on denatured collagen in the presence of anti-HU177 antibody was examined. Although targeting the HU177 epitope inhibited control B16F10 cell adhesion (Figure 6A) and migration (Figure 6C) on denatured collagen by approximately $40 \%$ to $50 \%$, no significant inhibition was observed with antiHU177 antibody when examining YAP-KD B16F10 cells under identical conditions (Figure 6, B and D), indicating that the ability of anti-HU177 antibody to inhibit B16F10 cell adhesion and migration depends on YAP.

Evidence indicates that ligation of both $\beta 1$ and $\beta 3$ integrins may result in activation and nuclear accumulation of YAP, ${ }^{16,34,36}$ and YAP is known to regulate multiple processes that contribute to tumor metastasis. Therefore, it was next determined whether the ability of the HU177 epitope to regulate metastasis depends on YAP. The role of YAP in regulating lung metastasis in the chick model was first assessed. As expected, reducing YAP in B16F10 cells inhibited experimental metastasis by over 70\% (Figure 6, E and F). Importantly, although reducing expression of YAP inhibited B16F10 lung colonization, it did not eliminate it. Though blocking the HU177 epitope significantly $(P<0.05)$ inhibited control-transfected B16F10 lung colonization (Figure $6 \mathrm{G}$ ), it failed to significantly reduce YAP-KD B16F10 cell lung colonization (Figure 6H). Similar results were also observed when evaluating the effects of the anti-HU177 antibody to inhibit B16F10 primary tumor growth, as anti-HU177 antibody inhibited the growth of B16F10 tumors expressing YAP, while exhibiting only minimal anti-tumor activity on B16F10 tumors in which Yap was knocked down (Supplemental Figure S1G).

\section{Discussion}

The combination of basic research and clinical observations has enhanced our understanding of the molecular mechanisms and genetic drivers that contribute to melanoma development and metastasis. ${ }^{36,37}$ Alterations in N-Ras, H-Ras, CDKN2A, and bRaf, which can lead to activation of MAPK/Erk and PI3K/Akt signaling, are among the most common changes thought to control melanoma tumor growth and metastasis. ${ }^{36-38}$ However, tumors are not simply a homogenous mass of transformed cells, but rather can be thought of as complex organs, composed of heterogeneous parenchyma and an integrated network of supporting stroma. ${ }^{39,40}$ Thus, many interconnected pathways operating within the tumor microenvironment regulate melanoma progression. This more comprehensive view of melanoma has led to exciting progress in the development of new targeted agents and immunotherapy. ${ }^{41,42}$ However, even with these exciting advances, not all patients respond to these therapies and multiple resistance mechanisms can develop. Thus, it is clear that more work is needed to develop more effective strategies for melanoma treatment.

The efficacy of many treatment strategies depends on selective regulation of integrated autocrine and paracrine signaling loops operating between tumor cells and the stroma. ${ }^{41-43}$ Uncovering new mechanisms by which the local tissue microenvironment governs tumor growth and metastasis are providing unique opportunities to develop more effective therapies. A common control point within the tumor microenvironment that integrates and coordinates the behavior of both tumor cells and different subpopulations of stromal cells is the ECM. New molecular insight into how the structural integrity and biophysical properties of collagen controls site-specific mechanotransduction pathways that alter cellular behavior is rapidly emerging. ${ }^{12-14,44} \mathrm{Here}, \mathrm{ev}-$ idence is provided for a novel therapeutic strategy to selectively disrupt ECM signaling that governs tumor growth and metastasis by specifically targeting a cryptic integrin binding site within collagen, rather than directly targeting the collagen binding integrins themselves. Here, it is shown that selectively targeting the HU177 epitope resulted in reduced levels of angiogenesis and $\alpha$-SMA-expressing stromal cells in B16F10 melanomas. Importantly, both endothelial cells and CAF-like stromal cells play roles in regulating tumor cell metastasis by multiple mechanisms ranging from the release of proteolytic enzymes that alter the structural integrity of the local ECM, release of protumorigenic growth factors, and chemokines that stimulate diverse signaling cascades that alter the migratory and invasive behavior of tumor cells, to regulating the innate and adaptive immune system by altering immune cell-mediated killing of malignant cells. 
A

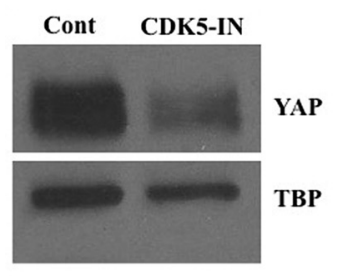

E

B16F10

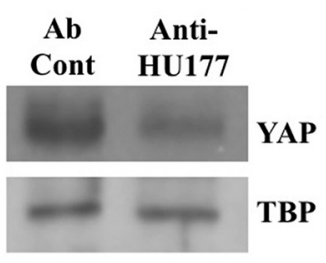

B

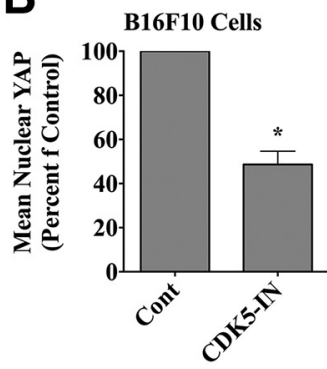

F

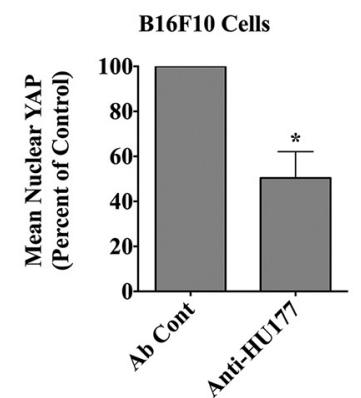

C B16F10

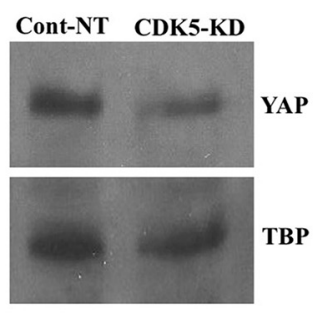

G $\quad$ B16F10

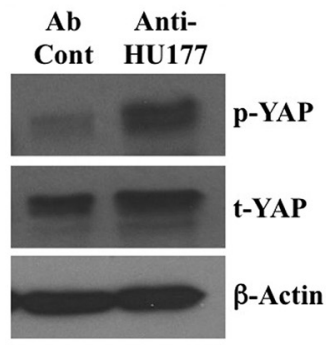

B16F10 Cells
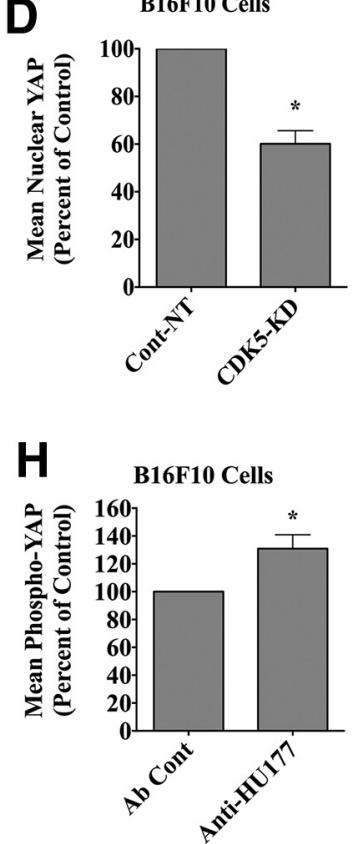

Figure 5 CDK5 plays a role in nuclear accumulation of YAP in B16F10 cells attached to denatured collagen. The relative levels of nuclear YAP were quantified in B16F10 cells treated with CDK5 inhibitor or in B16F10 cells in which Cdk5 was knocked down by shRNA. A: Example of a Western blot for nuclear YAP and TATA-binding protein from B16F10 cells pretreated with dimethyl sulfoxide or CDK5 inhibitor that were attached to denatured collagen. B: Quantification of mean relative change in the levels of nuclear YAP. C: Example of a Western blot for nuclear YAP and TATA-binding protein from control transfected B16F10 cells and Cdk5 shRNA - transfected B16F10 cells attached to denatured collagen. D: Quantification of mean relative change in nuclear YAP. E: Example of a Western blot for nuclear YAP and TATA-binding protein from B16F10 cells attached to denatured collagen pretreated with nonspecific control antibody or anti-HU177 antibody. F: Quantification of mean relative change in nuclear YAP. G: Example of a Western blot for phosphorylated YAP from B16F10 cells attached to denatured collagen pretreated with nonspecific control antibody or anti-HU177 antibody. H: Quantification of mean relative change in phosphorylated YAP. Data are expressed as means \pm SEM. $n=3$ experiments $(\mathbf{B}) ; n=8$ experiments $(\mathbf{D}) ; n=4$ experiments $(\mathbf{F}) ; n=5$ experiments $(\mathbf{H})$. ${ }^{*} P<0.05$ versus control. Ab Cont, control antibody; Anti-HU177, anti-HU177 epitope antibody; CDK5-IN, CDK5 inhibitor-treated; CDK5-KD, Cdk5 shRNA-transfected; Cont, control; Cont-NT, control-transfected; TBP, TATA-binding protein.

Expanding beyond the ability of the HU177 epitope to selectively regulate stromal cell behavior, these new data now indicate that the HU177 epitope directly governs the malignant behavior of melanoma cells themselves. It is well-established that both $\beta 1$ and $\beta 3$ integrins can regulate melanoma cell behavior, ${ }^{45-47}$ and it is interesting to point out that a major mechanism by which a humanized antiav $\beta 3$ antibody may function to inhibit tumor growth involves inducing antibody-dependent cellular cytotoxicity in cells that express $\alpha v \beta 3 .{ }^{48}$ Given that this integrin, as well as many $\beta 1$-containing integrins, is expressed in diverse cell types, including cells of the innate and adaptive immune system, the general strategy of directly targeting integrins may be detrimental to immune cell populations that are known to control tumor growth. Thus, it would be interesting to speculate that the limited clinical activity of direct anti-integrin therapy may in some cases be associated with inhibiting the adaptive and innate immune system, thereby limiting the overall efficacy of the direct integrin-targeting strategy.

As an alternative strategy to disrupt ECM signaling, the potential therapeutic activity of selectively targeting unique cryptic integrin-binding sites instead of directly targeting the integrin receptor itself was evaluated. ${ }^{12-17}$ Targeting specific cryptic integrin ligands can inhibit both angiogenesis and tumor growth, ${ }^{12-17}$ and has led to the development of an anti-HU177 collagen epitope antibody (D93/ TRC093), which was evaluated in a human clinical trial. $^{21,22}$ Although the results of this first clinical study were encouraging, a detailed molecular understanding of how the HU177 collagen epitope regulates tumor growth is not completely understood. Here, the first evidence is provided that blocking melanoma cell interactions with the HU177 epitope inhibits the phosphorylation of talin, a critical adaptor protein known to link integrins to the actin cytoskeleton and regulate downstream signaling pathways. Interestingly, although CDK5 is known to play a role in mediating phosphorylation of talin, ${ }^{30}$ this study's data indicate that blocking melanoma cell interactions with the HU177 epitope reduces the levels of phosphorylated CDK5.

Although studies are underway to define potential kinases and/or phosphatases that contribute to the differential phosphorylation of CDK5 and YAP by signaling through the HU177 epitope, these studies implicate CDK5 in regulating downstream signaling following melanoma 

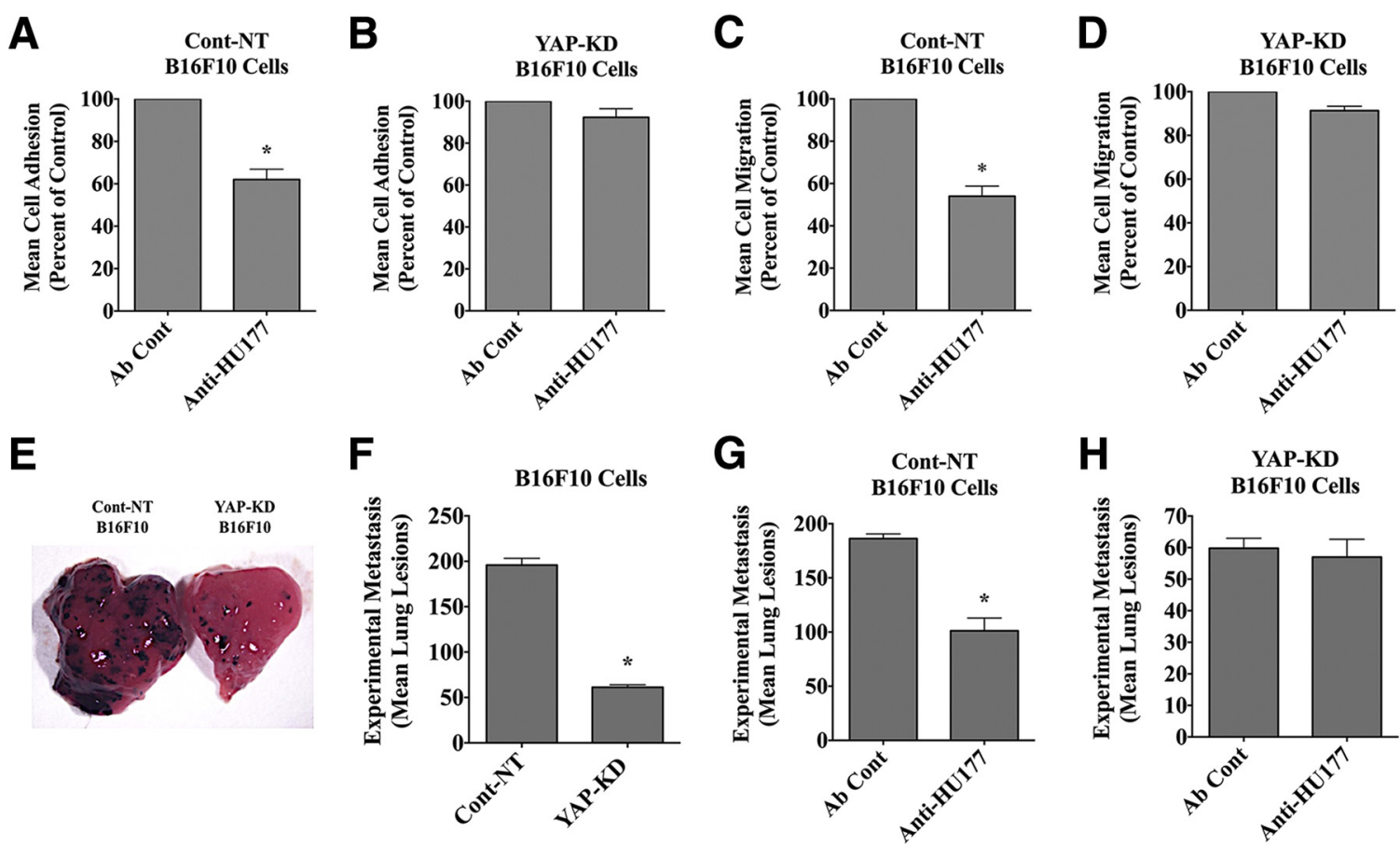

Figure 6 YAP plays a role in the ability of HU177 epitope to control B16F10 cell migration on denatured collagen and experimental metastasis. The ability of control transfected and anti-Yap shRNA-transfected B16F10 cells to attach and migrate on denatured collagen was examined. A: Quantification of B16F10 cell adhesion to denatured collagen in the presence of control antibody or anti-HU177 antibody. B: Quantification of anti-Yap shRNA-transfected B16F10 cell adhesion to denatured collagen in the presence of control antibody or anti-HU177 antibody. C: Quantification of control-transfected B16F10 cell migration on denatured collagen in the presence of control antibody or anti-HU177 antibody. D: Quantification of anti-Yap shRNA-transfected B16F10 cell migration on denatured collagen in the presence of control antibody or anti-HU177 antibody. E: Control and Yap knock down B16F10 cells were injected in chicks. Representative examples of pigmented B16F10 lung lesions from each condition. F: Quantification of pigmented B16F10 lung lesions from control and Yap knockdown cells. G: Quantification of control-transfected B16F10 lung colonization in the presence of control antibody or anti-HU177 antibody. H: Quantification of YAP-KD lung colonization in the presence of control antibody or anti-HU177 antibody. Data are expressed as means \pm SEM. $n=5$ experiments $(\mathbf{A}, \mathbf{C}$, and $\mathbf{D})$ and animals per condition $(\mathbf{G}$ and $\mathbf{H}) ; n=3$ experiments $(\mathbf{B}) ; n=6$ animals per condition $(\mathbf{F})$. ${ }^{*} P<0.05$ versus control. Ab Cont, control antibody; Anti-HU177, anti-HU177 epitope antibody; Cont-NT, control-transfected; YAP-KD, anti-Yap shRNA-transfected.

cell interactions with this cryptic collagen epitope. Although CDK5 regulates actin dynamics, tumor cell migration, and metastasis, the mechanisms by which this is mediated is not completely understood. This study provides new evidence for a signaling cascade initiated following interactions with the HU177 collagen epitope that controls melanoma cell metastasis in part by regulating the nuclear accumulation of YAP. This study's results indicate that inhibiting CDK5 or knocking down expression of CDK5 reduced nuclear accumulation of YAP in melanoma cells binding to denatured collagen, which is known to be selectively generated within the basement membrane of tumor vessels. These data are consistent with a novel role for CDK5 in controlling nuclear accumulation of YAP. YAP is well known to regulate tumor metastasis by controlling TEAD-transcription factor-dependent expression of multiple proangiogenic and promigratory molecules. ${ }^{49}$ Recent studies have also suggested that YAP can control mechanosensitive signaling and expression of genes associated with focal adhesion assembly and function. ${ }^{50}$ Thus, a more in-depth molecular understanding of how YAP is regulated within the tumor microenvironment may provide unique opportunities to design more effective and complementary strategies to selectively disrupt mechanosensitivesignaling cascades. Expanding on this idea, this study's new findings provide evidence for a previously unknown signaling pathway by which the HU177 cryptic epitope within collagen may locally reprogram melanoma cells by regulating nuclear localization of YAP by a CDK5dependent mechanism. Our studies indicate for the first time that the ability of melanoma cell interactions with the HU177 epitope to promote metastasis depends on YAP, because the anti-HU177 antibody failed to inhibit B16F10 cell metastasis of YAP knockdown cells, but readily inhibited B16F10 cell metastasis in cells expressing YAP. These data not only help to define a novel signaling pathway by which CDK5 governs nuclear YAP localization in melanoma cells, but also provide new insight into the mechanisms by which targeting of the HU177 epitope inhibits tumor growth and metastasis. This new understanding of how structural changes in collagen that surrounds tumor vessels may regulate melanoma cell behavior will likely accelerate the application of clinical 
strategies to disrupt ECM signaling either alone or in combination with other agents for the treatment of malignant tumors.

\section{Acknowledgment}

C8161 melanoma cells were a gift from Dr. Mary Hendrix (Children's Memorial Hospital, Chicago, IL).

\section{Supplemental Data}

Supplemental material for this article can be found at https://doi.org/10.1016/j.ajpath.2018.06.017.

\section{References}

1. Zhou L, Yang K, Andl T, Wickett R, Zhang Y: Perspective of targeting cancer-associated fibroblast in melanoma. J Cancer 2015, 6: $717-726$

2. Inada $\mathrm{M}$, Takita $\mathrm{M}$, Yokoyama $\mathrm{S}$, Watanabe $\mathrm{K}$, Tominari $\mathrm{T}$, Matsumoto S, Hirata M, Maru Y, Maruyama T, Sugimoto Y, Narumiya S, Uematsu S, Akira S, Murphy G, Nagase H, Miyaura C: Direct melanoma cell contact induces stromal cell autocrine prostaglandin E2-EP4 receptor signaling that drives tumor growth, angiogenesis, and metastasis. J Biol Chem 2015, 290:29781-29793

3. Cretu A, Brooks PC: Impact of the non-cellular tumor microenvironment on metastasis: potential therapeutic and imaging opportunities. J Cell Physiol 2007, 213:391-402

4. Bonnans C, Chou J, Werb Z: Remodeling the extracellular matrix in development and disease. Nat Rev Mol Cell Biol 2014, 15:786-801

5. Contois L, Akalu A, Brooks PC: Integrins as "functional hubs" in the regulation of pathological angiogenesis. Semin Cancer Biol 2009, 19: $318-328$

6. Raab-Westphal S, Marshall JF, Goodman SL: Integrins as therapeutic targets: successes and cancers. Cancers (Basel) 2017, 9. 110

7. Robinson SD, Hodivala-Dilke KM: The role of $\beta 3$-integrins in tumor angiogenesis: context is everything. Curr Opin Cell Biol 2011, 23: 630-637

8. Ramovs V, Te Molder L, Sonnenberg A: The opposing roles of laminin-binding integrins in cancer. Matrix Biol 2017, 57-58: $213-243$

9. Reynolds AR, Hart IR, Watson AR, Welti JC, Silva RG, Robinson SD, Da Violane G, Gourlaouen M, Salih M, Jones MC, Jones DT, Saunders G, Kostourou V, Perrom-Sierra F, Norman JC, Tucker GC, Hodivala-Dilke KM: Stimulation of tumor growth and angiogenesis by low concentrations of RGD-mimetic integrin inhibitors. Nat Med 2009, 15:392-400

10. Petitclerc E, Boutaud A, Prestayko A, Xu J, Sado Y, Ninomiya Y, Sarras MP Jr, Hudson BG, Brooks PC: New functions for noncollagenous domains of human collagen type IV: novel integrin ligands inhibiting angiogenesis and tumor growth in vivo. J Biol Chem 2000, 275:8051-8061

11. Pierschbacher MD, Ruoslahti E: Influence of stereochemistry of the sequence Arg-Gly-Asp-Xaa on binding specificity in cell adhesion. J Biol Chem 1987, 262:17294-17298

12. Xu J, Rodriguez D, Petitclerc E, Kim JJ, Hangai M, Yuen SM, Davis GE, Brooks PC: Proteolytic exposure of a cryptic site within collagen type IV is required for angiogenesis and tumor growth in vivo. J Cell Biol 2001, 154:1069-1079

13. Roth JM, Caunt M, Cretu A, Akalu A, Policarpio D, Li X, Gagne P, Formenti S, Brooks PC: Inhibition of experimental metastasis by targeting the HUIV26 cryptic epitope in collagen. Am J Pathol 2006, 168:1576-1586

14. Cretu A, Roth JM, Caunt M, Akalu A, Policarpio D, Formenti S, Gagne P, Liebes L, Brooks PC: Disruption of endothelial cell interactions with the novel HU177 cryptic collagen epitope inhibits angiogenesis. Clin Cancer Res 2007, 15:3068-3078

15. Akalu A, Roth JM, Caunt M, Policarpio D, Liebes L, Brooks PC: Inhibition of angiogenesis and tumor metastasis by targeting a matrix immobilized cryptic extracellular matrix epitope in laminin. Cancer Res 2007, 67:4353-4363

16. Ames JJ, Contois L, Caron JM, Tweedie E, Yang X, Friesel R, Vary C, Brooks PC: Identification of an endogenously generated cryptic collagen epitope (XL313) that may selectively regulate angiogenesis by an integrin yes-associated protein (YAP) mechanotransduction pathway. J Biol Chem 2016, 291:2731-2750

17. Caron JM, Ames JJ, Contois L, Liebes L, Friesel R, Muggia F, Vary $\mathrm{CPH}$, Oxburgh L, Brooks PC: Inhibition of ovarian tumor growth by targeting the HU177 cryptic collagen epitope. Am J Pathol 2016, 186:1649-1661

18. Pernasetti F, Nickel J, Clark D, Baeuerle PA, Van Epps D, Freimark B: Novel anti-denatured collagen humanized antibody D93 inhibits angiogenesis and tumor growth: an extracellular matrix-based therapeutic approach. Int J Oncol 2006, 29:1371-1379

19. Gagne PJ, Tihonov N, Li X, Glaser J, Qiao J, Silberstein M, Yee H, Gagne E, Brooks PC: Temporal exposure of cryptic collagen epitope within ischemic muscle during hindlimb reperfusion. Am J Pathol 2005, 167:1349-1359

20. Xu J, Rodriguez D, Kim JJ, Brooks PC: Generation of monoclonal antibodies to cryptic collagen sites by using subtractive immunization. Hybridoma 2000, 19:375-385

21. Freimark B, Clark D, Pernasetti F, Nickel J, Myszka D, Baeurle PA, Van Epps D: Targeting of humanized antibody D93 to sites of angiogenesis and tumor growth by binding to multiple epitopes on denatured collagens. Mol Immunol 2007, 44:3741-3750

22. Robert F, Gordon MS, Rosen LS, Mendelson DS, Mulay M, Adams BJ, Alvare D, Theure CP, Leigh BR: Final results from a phase 1 study of TRC093 (humanized anti-cleaved collagen antibody) in patients with solid cancer [abstract 3038]. J Clin Oncol 2010, 28 Suppl:3038

23. Ng B, Zakrzewski J, Warycha M, Christos PJ, Bajorin DF, Shapiro RL, Berman RS, Pavlick AC, Polsky D, Mazumdar M, Montgomery A, Liebes L, Brooks PC, Osman I: Shedding of distinct cryptic collagen epitope (HU177) in sera of melanoma patients. Clin Cancer Res 2008, 19:6253-6258

24. Hamilton HK, Rose AE, Chistos PJ, Shapiro RL, Berman RS, Mazumdar M, Ma MW, Krich D, Liebes L, Brooks PC, Osman I: Increased shedding of HU177 correlates with worse prognosis in primary melanoma. J Transl Med 2010, 8:19

25. Sahai E: Illuminating the metastatic process. Nat Rev Cancer 2007, 7 : 737-749

26. Ruiter D, Bogenrieder T, Elder D, Herlyn M: Melanoma-stroma interactions: structure and functional aspects. Lancet Oncol 2002, 3: 35-43

27. Wenke AK, Kjellman C, Lungren-Akerlund E, Uhlmann C, Haass NK, Herlyn M, Bosserhoff AK: Expression of integrin alpha10 is induced in malignant melanoma. Cell Oncol 2007, 29:373-386

28. Lawson C, Lim ST, Uryu S, Chen XL, Calderwood DA, Schlaepfer DD: FAK promotes recruitment of talin to nascent adhesions to control cell motility. J Cell Biol 2012, 196:223-232

29. Jin JK, Tien PC, Cheng CJ, Song JH, Huang C, Lin SH, Gallick GE: Talin 1 phosphorylation activates $\beta 1$ integrins: a novel mechanism to promote prostate cancer bone metastasis. Oncogene 2015, 34:1811-1821

30. Huang C, Rajfur X, Yousefi N, Chen Z, Jacobson K, Ginsberg MH Talin phosphorylation by CDK5 regulates Smurf1-mediated talin head ubiquitylation and cell migration. Nat Cell Biol 2009, 11: $624-630$ 
31. Bisht S, Nolting J, Schutte U, Haarmann J, Jain P, Shah D, Brossart P, Flaherty P, Feldmann G: Cyclin-dependent kinase 5 (CDK5) controls melanoma motility, invasiveness, and metastatic spread: identification of a promising novel therapeutic target. Transl Oncol 2015, 8:295-307

32. Shupp A, Casimiro MC, Pestell RG: Biological functions of CDK5 and potential CDK5 targeted clinical treatments. Oncotarget 2017, 8 : $17373-17382$

33. Zuckerberg LR, Patrick GN, Nikolic M, Humbert S, Wu CL, Lanier LM, Gertler FB, Vidal M, Van Etten RA, Tsai LH: Cables links $\mathrm{Cdk} 5$ and c-Abl and facilitates Cdk5 tyrosine phosphorylation, kinase upregulation, and neurite outgrowth. Neuron 2000, 26: 633-646

34. Zanconato F, Cordenonsi M, Piccolo S: YAP/TAZ at the roots of cancer. Cancer Cell 2016, 29:783-803

35. Lamar JM, Stern P, Liu H, Schindler JW, Jiang ZG, Hynes RO: The Hippo pathway target YAP promotes metastasis through its TEAD-interaction domain. Proc Natl Acad Sci U S A 2012, 109: E2441-E2450

36. Hodis E, Watson IR, Kryukov GV, Arold ST, Imielinski M, Theurillat JP, et al: A landscape of driver mutations in melanoma. Cell 2012, 150:251-263

37. Tsao H, Chin L, Garraway LA, Fisher DE: Melanoma: from mutations to medicine. Genes Dev 2012, 26:1131-1155

38. Lopez-Bergami P: The role of mitogen- and stress-activated protein kinase pathways in melanoma. Pigment Cell Melanoma Res 2011, 24: 902-921

39. Egnblad M, Nakasone ES, Werb Z: Tumors as organs: complex tissues that interfere with the entire organ. Dev Cell 2010, 18:884-901

40. Quail DF, Jones JA: Microenvironmental regulation of tumor progression and metastasis. Nat Med 2013, 19:1423-1437

41. Atkins MB, Larkin J: Immunotherapy combined or sequenced with targeted therapy in the treatment of solid tumors: current perspectives. J Natl Cancer Inst 2016, 108:djv414
42. Mahoney K, Rennert PD, Freeman GJ: Combination cancer immunotherapy and new immunomodulatory targets. Nat Rev Drug Discov 2015, 14:561-584

43. Alexander J, Cukierman E: Stromal dynamic reciprocity in cancer: intricacies of fibroblastic-ECM interactions. Curr Opin Cell Biol 2016, 42:80-93

44. Keely PJ: Mechanisms by which the extracellular matrix and integrin signaling act to regulate the switch between tumor suppression and tumor promotion. J Mammary Gland Biol Neoplasia 2011, 16: 205-219

45. Lydolph MC, Morgan-Fisher M, Hoye AM, Couchman JR, Wewer UM, Yoneda A: Alpha-9 beta 1 integrin in melanoma cells can signal different adhesion states for migration and anchorage. Exp Cell Res 2009, 315:3312-3324

46. Brooks PC, Stromblad S, Sanders LC, von Schalscha TL, Aimers RT, Setler-Stevenson WG, Quigley JP, Cheresh DA: Localization of matrix metalloproteinase MMP-2 to the surface of invasive cells by interaction with integrin $\alpha v \beta 3$. Cell 1996, 85: 683-693

47. Kuphal S, Bauer R, Bosserhoff AK: Integrin signaling in malignant melanoma. Cancer Metastasis Rev 2005, 24:195-222

48. Mulgrew K, Kinneer K, Yao XT, Ward BK, Damschroder MM, Walsh B, Mao SY, Gao C, Kiener PA, Coats S, Kinch MS, Tice DA: Direct targeting of $\alpha v \beta 3$ integrin on tumor cells with a monoclonal antibody, Abegrin. Mol Cancer Ther 2006, 5: 3122-3129

49. Liu X, Li H, Rajurkar M, Li Q, Cotton JL, Ou J, Zhu LJ, Goel HL, Mercurio AM, Park JS, Davis RJ, Mao J: Tead and AP1 coordinate transcription and motility. Cell Rep 2016, 14:1169-1180

50. Nardone G, Oliver-De La Cruz J, Vrbsky J, Martini C, Pribyl J, Skladal P, Pesl M, Caluori G, Pagliari S, Martino F, Maceckova Z, Hajduch M, Sanz-Garcia A, Pugno NM, Stokin GB, Forte G: YAP regulates cell mechanics by controlling focal adhesion assembly. Nat Commun 2017, 8:15321 